\title{
Enhancing the health of women living with HIV: the SMART/ESTWomen's Project
}

This article was published in the following Dove Press journal:

International Journal of Women's Health

I5 January 201 I

Number of times this article has been viewed

Stephen MWeiss'
Jonathan N Tobin'
Michael Antoni'
Gail Ironson'
Mary Ishii'
Anita Vaughn'
Andrea Cassells ${ }^{2}$
Deborah Jones'
Neil Schneiderman'
Elizabeth Brondolo
Arthur LaPerriere'
Maria Lopez'
Olga Villar-Loubet'
Joanne Camille ${ }^{2}$
Mahendra Kumar'
J Bryan Page'
SMART/EST Women's
Project Team*
'University of Miami, Miami, FL, USA;
'Clinical Directors Network, New
York, NY, USA; 'St Johns University,
Queens, NY, USA; *The SMART/EST
Womens' Project Team: DeVieux J,
Jean-Gilles M, Gousse Y, Alexander
K, Bustamonte V, Lopez E, Casani J,
Stanley H, Asthana D, Van Splunteren F,
Goldstein A, Nasajon R, WiesnerY,
Zukerman M, Segal--Isaacson CJ,
Romanowsky, Masheb R, Coma C,
Ubiera M, D'Andrea SM, Ittai N.

Correspondence: Stephen M Weiss Department of Psychiatry and Behavioral Sciences, University of Miami Miller School of Medicine, Miami, Florida 33136, USA

Tel 305-243-2103

Fax 305-243-2I 26

Email sweiss2@med.miami.edu
Abstract: The principal objective of these multisite studies (Florida, New York, New Jersey: epicenters for human immunodeficiency virus [HIV] among women) was to develop and implement effective combinations of behavioral interventions to optimize the health status of the most neglected and understudied population affected by the acquired immunodeficiency syndrome (AIDS) epidemic in the United States: poor women of color living with HIV. The two studies enrolled nearly 900 women randomly assigned to "high intensity" (cognitive-behavioral stress management training combined with expressive-supportive therapy [CBSM]+ group) or "low intensity" (individual psychoeducational program) treatment conditions over a period of 9 years. The initial study of the stress management and relaxation training/expressive-supportive therapy (SMART/EST) Women's Project (SWP I) focused on reducing depression and anxiety, as well as improving self-efficacy and overall quality of life for women with case-defined AIDS. Findings from this study demonstrated the utility of CBSM+ in reducing distress (depression, anxiety) and denial, while improving social support, self-efficacy, coping skills, and quality of life. The second study (SWP II), which included all women living with HIV, extended these findings by demonstrating that exposure to CBSM+ significantly improved the ability of the participants to take advantage of a health behavior change program encouraging the adoption and maintenance of healthier lifestyle behaviors (high levels of medication adherence, appropriate nutritional intake and physical activity, safer sexual practices, and reduced alcohol use/abuse) essential for optimal health in the context of living with HIV. SWP II also determined that the intervention program was equally beneficial to less-acculturated segments of the affected population (ie, non-English speaking HIV+ women) through the creation of culturally and linguistically sensitive Spanish and Creole versions of the program. A third study (SWP III) is currently underway to "translate" this evidence-based treatment program into Community Health Centers in Miami, New York City, and metropolitan New Jersey.

Keywords: HIV, AIDS, behavior, social support, viral load, quality of life, translating research into practice

\section{Introduction}

Over the past decade, women in the USA, particularly poor women of minority status, have experienced a $20 \%$ increase in rates of new human immunodeficiency virus (HIV) infections and acquired immunodeficiency syndrome (AIDS) cases, ${ }^{1} 28 \%$ of all newly identified AIDS cases and $30 \%$ of HIV diagnoses are women. ${ }^{1,2}$ Minority women are disproportionately represented among HIV cases, with rates (per 100,000 population) for African-American and Hispanic females of 56 and 13.3, respectively, compared to 2.9 for white women. ${ }^{1}$ Although African-Americans and Hispanics represent $12 \%$ and $15 \%$ of the women in the USA respectively, they account for over $80 \%$ of all female HIV and AIDS cases. 
In 2007, the rate of AIDS diagnoses in New York City (per 100,000 population) was 24.9 , of which $52 \%$ were African American and $30 \%$ were Hispanic. ${ }^{2,3}$ While national data are not available for other Black populations, Haitian women account for $16 \%$ of all HIV cases in women in Miami-Dade County, Florida. ${ }^{4}$

Florida and New York are first and second for new HIV cases in women, with $38 \%$ of new HIV cases and $31 \%$ of AIDS cases in Florida being female, and with higher rates among heterosexuals, women, and African Americans than the national average. ${ }^{5}$ Most women with HIV have contracted the virus through heterosexual contact or injecting drugs. ${ }^{6,7}$

With the increased rates of survival, due in large part to the advent of effective antiretroviral therapy (ARV), HIV has shifted from a terminal illness to a chronic (but transmissible) disease, requiring long-term adherence to pharmacologic and behavioral regimens. Delivery of medication adherencepromoting strategies by primary care clinicians requires the integration of effective behavioral/mental health services into primary care. ${ }^{8-13}$

New classes of ARVs continue to dramatically alter the progression of disease and associated morbidity and mortality in persons living with HIV. ${ }^{14-16}$ Prevention of HIV transmission becomes an even greater public health challenge as more HIV+ persons continue to be sexually active with both HIV- and HIV+ partners. ${ }^{17}$ ARV therapy has adverse side effects, which may also increase the risk for other chronic diseases, such as diabetes, metabolic syndrome, hyperlipidemia, hypertension, and cardiovascular disease. Therefore, to maintain high levels of quality of life (QoL) and to reduce the risks of other chronic diseases, health services provided for persons living with HIV must also include attention to comorbid conditions and associated lifestyle behaviors. Effective treatment for this population involves a complex set of changes in health-related behaviors, which include adjusting to a devastating diagnosis, adhering to daunting medication regimens, and modifying their diet, physical activity levels, sexual practices, and substance use. ${ }^{18}$ This paper will present a compendium of findings from two completed studies demonstrating the effects of behavioral interventions designed to promote adjustment in HIVinfected women of color. Already published results will be referenced, while new data will be cited with relevant statistical parameters.

The stress management and relaxation training/ expressive-supportive therapy (SMART/EST) Women's Program (SWP) (see Figure 1) was designed to enhance QoL and improve health status for ethnically diverse, disadvantaged women living with HIV. Over the past 10 years, this research team has developed, adapted, and tested a multicultural, multilingual "healthy lifestyles" intervention program tailored to the needs of this population. The SWP I intervention consists of 10 weekly 2-hour group cognitive-behavioral stress management/expressive-supportive therapy (CBSM+) intervention sessions. SWP II followed the 10 sessions with an additional six weekly Group Healthy Living promotion program sessions. The CBSM+ component of the intervention includes a series of exercises designed to: 1) provide information on stress responses and coping; 2) teach anxiety reduction skills (ie, progressive muscle relaxation, deep

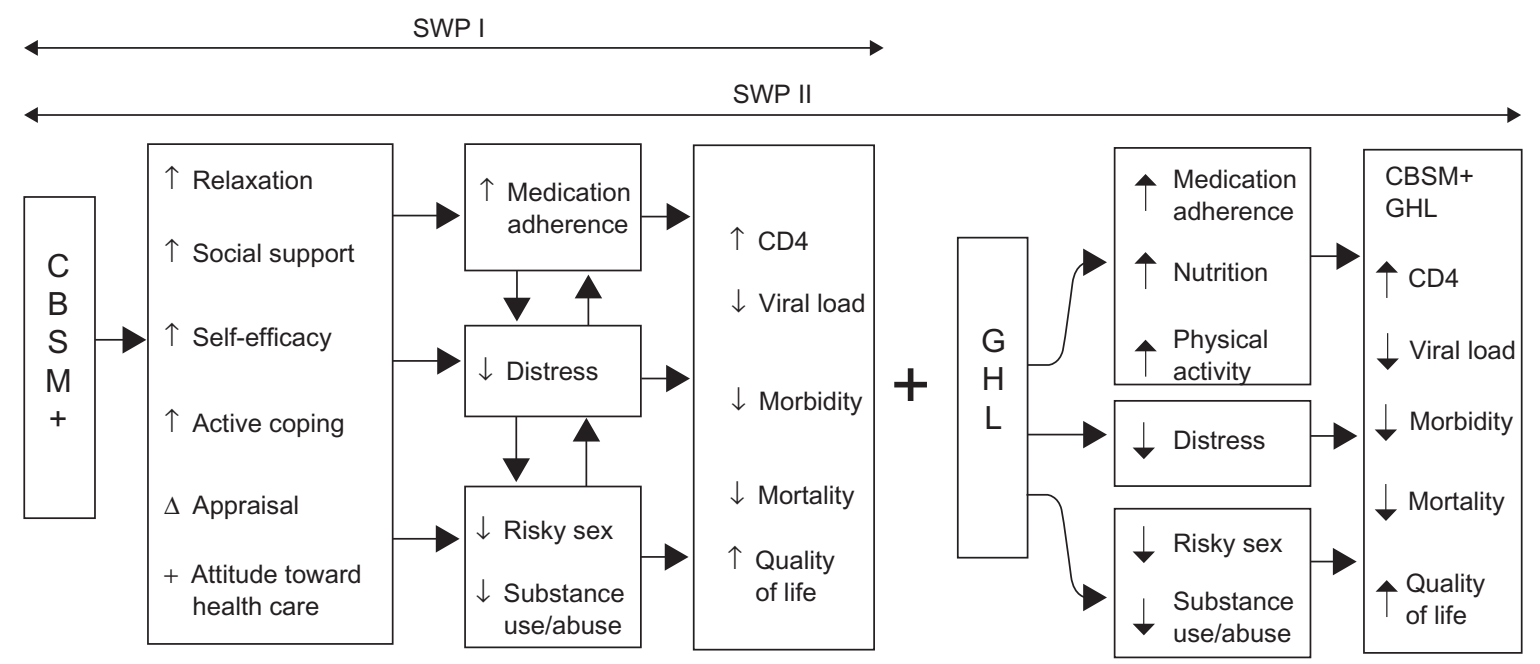

Figure I Stress management and relaxation training/expressive-supportive therapy (SMART/EST) Women's Program (SWP) theoretical model. Copyright (C I999, Informa Health care. Adapted with permission from Schneiderman N. Behavioral medicine and the management of HIV/AIDS. Int J Behav Med. I999;6:2-I4.48 Abbreviations: CBSM+, cognitive-behavioral stress management training combined with expressive-supportive therapy; GHL, Group Healthy Living. 
breathing and guided imagery, autogenic suggestion, physical activity); 3) modify maladaptive cognitive appraisals using cognitive restructuring, reframing strategies, and disputing irrational beliefs; 4) enhance interpersonal conflict resolution skills and anger management via negotiation skills training; 5) encourage participants to use active, problem-solving coping strategies rather than passive, emotion-based coping, where appropriate; 6) provide a supportive group environment for the open expression of feelings and thoughts; 7) increase utilization of social support networks, as well as appropriate health care and community resources; and 8) increase knowledge, change attitudes, and improve adherence to the healthy living components.

The CBSM+ component also includes gender, language, and culture-relevant CBSM training (eg, cultural issues related to relationships, illness, and health care), self-management techniques (eg, learning to recognize antecedents of conflict and to control impulses to engage in maladaptive and unproductive coping responses), and assertiveness training (eg, role-playing appropriate communication strategies), presented within an EST framework. The Group Healthy Living component includes 12 contact hours focused on medication adherence, nutrition, safer sex, substance abuse reduction, and physical activity. The intervention is fully manualized and deliverable as a 16-session program using the CBSM+ framework embedded in the didactic portion to support the Group Healthy Living component.

These studies evaluated whether an empirically validated depression reduction and stress management intervention which had demonstrated efficacy with highly educated gay men with AIDS, ${ }^{19}$ could be successfully adapted to the needs of low income minority women. We sought to determine whether CBSM+ could impact QoL and overall health status of low income, minority women living with HIV by comparing $\mathrm{CBSM}+$ to an individually delivered psychoeducational intervention. This paper summarizes these findings from the first two SWPs (SWP I and SWP II).

\section{Methods}

SWP I implemented the program in two venues: a medical school setting using university-based clinicians (Miami), and in Community Health Centers (CHCs) supported by the Health Resources and Services Administration (HRSA), using "imported" contracted university-based clinicians (metropolitan New York/New Jersey [NY/NJ]).

SWP II was designed to generalize the findings of SWP I to a broader population by expanding the inclusion criteria to all women infected with HIV (not just women with case-defined AIDS), including those with current substance abuse and with decreased cognitive functioning. SWP II also included women who spoke English, Spanish, or Haitian Creole as their principal language. SWP II tested the hypothesis that participants who acquired the CBSM+ skills would gain more from a health promotion intervention (Group Healthy Living) than those who did not acquire these skills.

\section{Recruitment}

Recruitment for SWP I began in February 1997, and recruitment for SWP II was completed by August 1, 2005. Across both trials, 933 study participants were enrolled from Miami, New York, and New Jersey. In SWP I, 451 women were randomized to either the CBSM+ group intervention $(n=212)$ or an individual psychoeducational (ie, high-quality "usual care") condition $(\mathrm{n}=239)$. Participants included Englishspeaking women who were aged 18 years or older and who met the Centers for Disease Control and Prevention (CDC) guidelines for case-defined AIDS. Follow-up included posttreatment, 6-month, and 12-month assessments.

For SWP II, participants $(n=482)$ consisting of HIV+ women who spoke English $(\mathrm{n}=237)$, Spanish $(\mathrm{n}=185)$, or Haitian Creole $(n=60)$, were randomized to receive 10 sessions of either a CBSM+ group intervention or the individual psychoeducational condition. This was followed by a second randomization in which participants received six additional sessions of either Group Healthy Living or Individual Health Promotion. Assessments were administered at baseline and repeated at post-intervention, 6, 12, and 24 months.

In the initial study (SWP I), participation was limited to women with CDC case-defined AIDS (CD $<200$ or $\geq 2$ opportunistic infections). Subsequent studies (SWP II and SWP III) included all women diagnosed with HIV. Participation in the study was voluntary, and all participants were compensated for time, childcare, and transportation expense (\$25 per session). Of those potentially eligible, approximately one third agreed to participate.

\section{Screening}

\section{Structured clinical interview - DSM-IV (SCID)}

Following recruitment, subjects were screened for specified DSM-IV (Diagnostic and Statistical Manual of Mental Disorders, 4th Edition) psychiatric disorders by $\mathrm{PhD}$ level psychologists using the Structured Clinical Interview for DSM-IV ${ }^{20}$ adapted for use with nonpatient participants with HIV infection (SCID-NP-HIV). ${ }^{21}$ Specific modules from 
this interview were used to evaluate current (within the past 3 months) and lifetime psychotic and mood disorders.

Drug and alcohol abuse and dependency were measured by the SCID-NP-HIV, Drug and Alcohol module. At baseline the participant's history and current abuse/dependency status were assessed. At all other time points, current abuse/dependency was assessed since the last time interviewed for this study.

\section{Assessment}

The variables assessed in this study were in accordance with our conceptual model (Figure 1). We grouped the measures into: 1) screening, 2) primary psychosocial outcome variables (depression, anxiety, AIDS-specific distress, QoL), 3) Healthy Living primary adherence outcome variables (adherence to medication, diet, safer sex, physical activity, substance use/abuse reduction), 4) primary biomedical outcome variables (viral load, CD4, CD8, sexually transmitted diseases, and health care utilization), and 5) mediating variables (eg, coping, self-efficacy) or moderating variables (eg, social support, acculturation) (see Tables 1A to 1E). All assessment instruments for SWP II were translated into Spanish and Creole, incorporating cultural brokerage theory throughout the translation process..$^{22-24}$

\section{Cultural/linguistic translation of psychosocial measures}

Although the resources necessary for full psychometric analyses of all assessment instruments with each of our cultural/linguistic groups were not available, the research team addressed issues of reliability, and content and construct validity in our pilot study to ensure relevance of both assessment and intervention protocols for our monolingual Hispanic and Haitian participants. Procedures were as follows:
1. Focus groups comprised of cultural/linguistic experts and graduates of earlier intervention groups reviewed all assessment instruments and all elements of the intervention for cultural appropriateness and validity (having similar meanings in both languages).

2. Translated and back-translated all assessments and intervention materials.

3. Evaluated final translated versions of assessment instruments and intervention materials for conveyance of intended meaning.

Upon completion of the translation and back-translations, less than $10 \%$ of the translated items required additional adjustments for conveyance of meaning. Once these translations and adjustments were complete, it was possible to administer the entire battery of assessments to women who were monolingual in Spanish or Creole. These pilot efforts to ensure cultural appropriateness and accurate conveyance of meaning demonstrated high content validity for our assessment and intervention strategies with monolingual participants. In addition, we conducted tests of reliability and construct validity on measures of distress (the Beck Depression Index [BDI] and the Impact of Event Scale) and QoL (Medical Outcomes Study) (see Tables 2 and 3).

\section{Intervention}

Intervention goals and strategies

One of the principal aims of both studies (SWP I and SWP II) was to improve the overall health status and QoL for our participants. SWP I determined that low-income minority women living with AIDS could benefit from an intense 10-week program using $\mathrm{CBSM}+$ to reduce distress and improve QoL.

Table IA Psychosocial outcome measures

\begin{tabular}{|c|c|c|}
\hline Assessment & Author & Constructs measured \\
\hline \multicolumn{3}{|l|}{ Depressed affect and anxiety } \\
\hline Beck Depression Inventory (BDI) & Beck et a ${ }^{49}$ & Depression \\
\hline \multirow{2}{*}{ Structured Clinical Interview for DSM-III-R (SCID) } & First et $\mathrm{al}^{20}$ & Current depression \\
\hline & & Depression symptoms and HIVIAIDS symptoms differentiation \\
\hline Speilberger State-Trait Anxiety Inventory (STAI) & Spielberger et $\mathrm{a}^{50}$ & Anxiety \\
\hline \multicolumn{3}{|l|}{ AIDS-specific distress } \\
\hline Impact of Events Scale (IES) & Horowitz et $\mathrm{a}^{51}$ & $\begin{array}{l}\text { Intrusion subscale: experiences of daydreams, unwanted images, } \\
\text { and dreams associated with stressor. } \\
\text { Avoidance subscale: awareness of distraction from ideas, } \\
\text { feelings, or situations surrounding stressor. }\end{array}$ \\
\hline
\end{tabular}


Table IB Health behavior outcome measures

\begin{tabular}{|c|c|c|}
\hline Assessment & Author & Construct measured \\
\hline \multicolumn{3}{|l|}{ Adherence to antiretroviral medication } \\
\hline Adherence to Medication Scale (AMS) & Chesney et $\mathrm{al}^{53}$ & Adherence to antiretroviral medication \\
\hline \multicolumn{3}{|l|}{ Sexual risk behavior } \\
\hline $\begin{array}{l}\text { Adult Sexual Risk Behavior Assessment } \\
\text { Schedule (SERBAS) }\end{array}$ & Meyer-Bahlburg et $\mathrm{al}^{54}$ & $\begin{array}{l}\text { Sexual risk and IV drug use factors for HIV } \\
\text { transmission }\end{array}$ \\
\hline \multicolumn{3}{|l|}{ Sexual barrier use } \\
\hline Barrier Method Questionnaire & $\begin{array}{l}\text { UCSF CAPS Barrier Questionnaire; } \\
\text { Family Health International }{ }^{55}\end{array}$ & $\begin{array}{l}\text { Women's motives and preference for sexual } \\
\text { barrier use }\end{array}$ \\
\hline \multicolumn{3}{|l|}{ Nutrition } \\
\hline $\begin{array}{l}\text { Rapid Eating and Activity Assessment for } \\
\text { Patients (REAP-S) }\end{array}$ & Gans et $\mathrm{al}^{56}$ & Food group adequacy and excess \\
\hline \multicolumn{3}{|l|}{ Physical activity } \\
\hline Stanford 7-day Activity Recall (7-DR) & Sallis et $\mathrm{al}^{57}$ & $\begin{array}{l}\text { Physical activity specific to } 7 \text { days prior to } \\
\text { administration of assessment }\end{array}$ \\
\hline \multicolumn{3}{|l|}{ Alcohol use } \\
\hline Miami Alcohol Use Questionnaire & Ironson (Unpublished) ${ }^{58}$ & $\begin{array}{l}\text { Current use, frequency, and amount } \\
\text { of alcohol }\end{array}$ \\
\hline \multicolumn{3}{|l|}{ Drug use } \\
\hline $\begin{array}{l}\text { Adult Sexual Risk Behavior Assessment } \\
\text { Schedule (SERBAS) }\end{array}$ & Meyer-Bahlburg et $\mathrm{al}^{54}$ & $\begin{array}{l}\text { Sexual risk and IV drug use factors for HIV } \\
\text { transmission }\end{array}$ \\
\hline SCID-NP-HIV Drug Use Dependency Module & First et $\mathrm{al}^{20}$ & $\begin{array}{l}\text { Current use, frequency, and amount of } \\
\text { drug use }\end{array}$ \\
\hline \multicolumn{3}{|l|}{ Health care utilization } \\
\hline Social Service and Utilization Schedule (SSUS) & Kaminsky et al ${ }^{59}$ & Social Service and Utilization Schedule (SSUS) \\
\hline
\end{tabular}

Abbreviations: HIV, human immunodeficiency virus; IV, intravenous.

Table IC Moderator variables: functional quality of life, acculturation, relationship violence, AIDS-specific coping strategies, cognitive functioning, and religiosity

\begin{tabular}{|c|c|c|}
\hline Assessment & Author & Construct measured \\
\hline \multirow[t]{2}{*}{ Karnofsky Activities of Daily Living Scale (ADL) } & Karnofsky et $a^{60}$ & Quality of life \\
\hline & & Gross functional impairment \\
\hline Szapocznik Behavioral Acculturation and & Szapocznik et al ${ }^{61}$ & Level of acculturation to the host culture \\
\hline \multirow[t]{2}{*}{ Biculturalism Scales (SBABS) } & Szapocznik et al ${ }^{62}$ & Degree of participation in cultural pluralism \\
\hline & Szapocznik and Kurtines ${ }^{63}$ & \\
\hline Psychological Acculturation Scale (PAS) & Tropp et $\mathrm{al}^{64}$ & Individual's perception of cultural identity: psychological \\
\hline & & attachment to culture of origin \\
\hline \multirow[t]{5}{*}{ COPE (situational version) } & Carver et $\mathrm{al}^{65}$ & Active/Involvement Strategies scale: active coping, \\
\hline & & planning, acceptance, seeking emotional support, and \\
\hline & & seeking instrumental support. \\
\hline & & Denial/Disengagement Strategies scale: denial, mental \\
\hline & & disengagement, behavioral disengagement. \\
\hline \multirow[t]{3}{*}{ HIV Dementia Scale (HDS) } & Power et $\mathrm{al}^{66}$ & Degree of subcortical HIV dementia via \\
\hline & & memory, attention, psychomotor, and \\
\hline & & construction assessments \\
\hline Folstein Mini-Mental State Exam (MMSE) & Folstein et $\mathrm{al}^{67}$ & Measure of cortical functioning \\
\hline
\end{tabular}

Abbreviations: AIDS, acquired immunodeficiency syndrome; HIV, human immunodeficiency virus.

Table ID Mediator variables: self-efficacy and social support

\begin{tabular}{lll}
\hline Assessment & Author & Construct measured \\
\hline Self-Efficacy Inventory (SEI) & Ironson et a ${ }^{68}$ & Perceived efficacy to manage future HIV/AIDS \\
Social Support Questionnaire (SSQ) & Hinkle et al ${ }^{69}$ & symptoms and stressors via CBSM strategies \\
& Sarason et al ${ }^{70}$ & Perceived quantity and quality of emotional and \\
\hline
\end{tabular}

Abbreviations: AIDS, acquired immunodeficiency syndrome; CBSM, cognitive-behavioral stress management; HIV, human immunodeficiency virus. 
Table IE Biomedical outcome measures

\begin{tabular}{|c|c|c|}
\hline Assessment & Author & Construct measured \\
\hline \multicolumn{3}{|l|}{ Viral load } \\
\hline Reverse Transcriptase Polymerase Chain Reaction & Winters et $\mathrm{al}^{71}$ & Quantitate blood HIV-I RNA levels \\
\hline \multicolumn{3}{|l|}{ Amplicor HIV Monitor Ultra-sensitive Kit Assay } \\
\hline \multicolumn{3}{|l|}{ CD4 and CD8 cell counts } \\
\hline Color flow cytometry & Kidd and Nicholson ${ }^{72}$ & $\begin{array}{l}\text { Number and percent of } \mathrm{T} \text { cells and subsets } \\
\text { using monoclonal antibodies }\end{array}$ \\
\hline \multicolumn{3}{|l|}{ Sexually transmitted diseases } \\
\hline Polymerase chain reaction amplification technology & Burczac et $\mathrm{al}^{73}$ & $\begin{array}{l}\text { Detection of Chlamydia trachomatis and } \\
\text { Neisseria gonorrhea }\end{array}$ \\
\hline Syphilis RPR & Public Health Service ${ }^{74}$ & $\begin{array}{l}\text { Rapid detection and quantitative } \\
\text { determination of syphilis in serum or plasma }\end{array}$ \\
\hline \multicolumn{3}{|l|}{ Anthropometric measures } \\
\hline $\begin{array}{l}\text { Height, weight, body mass index, waist-hip ratio, upper arm } \\
\text { and thigh circumference, height-for age, and weight-for-height } \\
\text { measurements }\end{array}$ & & Nutrition and physical activity tracking \\
\hline Bio-electrical impendance analysis & Segal et $\mathrm{al}^{75}$ & Measures percentages of body cell mass \\
\hline Tanita Body Composition Analyzer TBF 300A & Coodley et $\mathrm{al}^{76}$ & made of water and fat \\
\hline
\end{tabular}

Abbreviations: HIV, human immunodeficiency virus; RNA, ribonucleic acid; RPR, rapid plasma reagin.

SWP II expanded the intervention to determine whether exposure to the CBSM+ intervention would significantly improve the adoption and maintenance of HIV-relevant health behaviors ("Healthy Living"). The intervention was structured to establish a CBSM-based problem solving and coping strategy skill foundation to which HIV-specific health promotion Healthy Living issues were added, ie, medication adherence, nutrition, safer sex, physical activity, and substance use/abuse risk reduction.

To test the efficacy of this approach in SWP II, we employed a two-stage factorial design in which eligible participants were randomized to a 10 -week session "high intensity" CBSM+ group condition or a 10-week session "low intensity" individual psychoeducational condition (ie, highquality "usual care") consisting of educational videos and written handout materials similar in informational content to the group condition. Following completion of the first 10 weeks, participants were randomized by group or cohort to a six-biweekly session "high intensity" Group Healthy Living condition or a "low intensity" Individual Health Promotion condition of similar length and content, using educational videos and written handout materials. These four conditions

Table 2 Comparative cultural construct validity outcome measures

\begin{tabular}{lll}
\hline Outcome measure & English & $\begin{array}{l}\text { Spanish and } \\
\text { Creole }\end{array}$ \\
\cline { 2 - 3 } & Pearson $\boldsymbol{r}$ & Pearson $\boldsymbol{r}$ \\
\hline Beck Depression Inventory & 0.80 & 0.93 \\
Impact of Events Scale (total) & 0.90 & 0.87 \\
Medical Outcomes Survey (total) & 0.70 & 0.70 \\
\hline
\end{tabular}

allowed us to test in a well controlled design, the relative value of the CBSM+ intervention and the Group Healthy Living condition, individually and in combination, for changing behaviors relevant to optimal health as compared with less intense, more typical "usual care" conditions.

The primary goals of the first 10 sessions were to: 1) provide participants with information on stress responses and coping; 2) teach anxiety reduction skills such as progressive muscle relaxation and guided imagery; 3) modify maladaptive cognitive appraisals using cognitive restructuring and reframing strategies; ${ }^{25} 4$ ) enhance interpersonal conflict resolution skills and anger management via negotiation skills training; 5) encourage participants to use active, problemsolving coping strategies rather than passive, emotion-based coping, where feasible; 6 ) provide a supportive group environment for the open expression of feelings and thoughts; and

Table 3 Comparative cultural internal reliability

\begin{tabular}{lll}
\hline Outcome measures & English & $\begin{array}{l}\text { Spanish and } \\
\text { Creole }\end{array}$ \\
\cline { 2 - 3 } & $\begin{array}{l}\text { Cronbach's } \\
\text { alpha }\end{array}$ & $\begin{array}{l}\text { Cronbach's } \\
\text { alpha }\end{array}$ \\
\hline $\begin{array}{l}\text { Beck Depression Inventory } \\
\text { and State Trait Anxiety }\end{array}$ & $0.6 \mathrm{I}$ & 0.69 \\
$\begin{array}{l}\text { Inventory/Trait (total) } \\
\text { Beck Depression Inventory }\end{array}$ & $0.5 \mathrm{I}$ & \\
$\begin{array}{l}\text { and State Trait Anxiety } \\
\text { Inventory/State (total) } \\
\text { Beck and Impact of Events }\end{array}$ & 0.34 & $0.7 \mathrm{I}$ \\
$\begin{array}{l}\text { Scale (total) } \\
\text { Beck and Medical Outcomes }\end{array}$ & -0.55 & 0.59 \\
\begin{tabular}{l} 
Survey (total) \\
\hline
\end{tabular} & & $-0.7 \mid$ \\
\hline
\end{tabular}


7) increase utilization of social support networks. The primary goals of Healthy Living were to increase knowledge, change attitudes and improve adherence concerning 1) medication regimens, 2) nutritional intake, 3) safer sex, 4) physical activity, and 5) substance use/abuse risk reduction.

Participants differed in preferred coping style and perceived stressor controllability. ${ }^{26}$ Therefore, during the first 10 weeks, participants identified those CBSM techniques (from a wide variety offered) that were most helpful and suited their own circumstances most closely. During the Healthy Living component, participants had the opportunity to apply specific CBSM techniques to the adoption and maintenance of the aforementioned behaviors related to improving health and QoL, as well as reducing HIV transmission.

\section{Cultural adaptation of the intervention}

Extensive changes were made to the intervention to make it more suitable for minority women who principally spoke English, Spanish, or Haitian Creole. As our participants were predominantly African-American, Haitian-American, or Latina women, exercises and examples within the modules were revised to reflect cultural values; for example, the role of familial relationships, spirituality, and the church in enhancing social support. A number of exercises previously conducted as individual, written in-session exercises were modified to reflect the educational level of the majority of our participants, and were converted to group oral exercises. These adaptations also reflected the cultural values emphasizing oral rather than written expression, and collective rather than individual activities. In addition, the modules incorporated examples relevant to participants in substance abuse recovery; for example, "The Serenity Prayer" was used in the coping module to demonstrate the importance of applying the appropriate coping responses (emotion-focused versus problem-focused) to specific stressors. Every effort was made to have at least one of the two female therapists be a member of the ethnic groups represented by study participants. Both therapists were experienced in working with individuals from the relevant ethnic groups to ensure that participants' thoughts, feelings, and behavioral responses to stressors were understood within the appropriate cultural context.

A cultural/linguistic working group was responsible for tailoring the program to the culture-specific needs and issues of our less acculturated English-speaking participants. It also was responsible for overseeing the linguistic accuracy and equivalence in meaning for all translated materials for those HIV+ women who were monolingual in Spanish or Creole. In addition to translation and back-translation of all materials, the cultural/linguistic working group engaged in a "cultural brokerage" process, whereby the contextual material from our pilot studies of monolingual Spanish- and Creole-speaking groups, plus focus groups and ethnographic interviews, was carefully reviewed to ensure that culturespecific values, mores, and perspectives were integrated into the intervention process and content.

\section{Intervention format}

CBSM+ was a 10-session, closed, structured group intervention, meeting once weekly for approximately 135 minutes per session over a period of 10 weeks. The CBSM+ intervention provided an EST environment within which participants were trained in CBSM techniques. The intervention sessions were modified by participant and therapist feedback, increasing the EST component to respond to participant needs to focus on HIV themes; for example, mortality, HIV stigma, spirituality, and cultural issues. The informational component of the CBSM+ intervention focused on learning to cope with daily stressors associated with HIV-related health problems and learning about social resources. In tailoring this group intervention for the target populations, we were acutely aware of the importance of maximizing the cultural appropriateness of our treatment aims and strategies for all participants. The cultural/ linguistic planning group was charged with the responsibility for addressing these issues in all phases of the program.

The development of the Healthy Living component of the SWP II intervention was based upon the acknowledged importance of a variety of health-enhancing behaviors relevant to maintaining optimal health for persons living with HIV. It consisted of six group sessions meeting biweekly for approximately 150 minutes per session over a period of 12 weeks. The sessions included five modules: medication adherence, nutrition, safer sex, physical activity, and substance use/abuse reduction, in video, didactic, and interactive formats. The Healthy Living intervention addressed specific HIV-related health behaviors and included relevant discussion material and problem-solving exercises; for example, memory aids to increase medication adherence, safer sex strategies, and techniques to enhance nutritional status and levels of physical activity.

The Healthy Living intervention focused on barriers to using medication and implementing behavioral solutions to increase adherence, social support, and coping with side effects and medication concerns. Additionally, the importance of nutrition in improving and maintaining the health of persons living with HIV was discussed, as well as the impact of certain types of foods on ARV medications. Also 
considered were cultural preferences and local availability of produce when discussing changing food choices, preparation methods, portion sizes, and using foods that were available within the local markets rather than replacing foods or using unfamiliar ingredients.

The intervention also focused on the correct way to use sexual barrier products (male and female condoms) and a review of the New York Hierarchy of sexual risk reduction. ${ }^{27}$ Participants were supplied with sexual barrier products and low-literacy level printed materials, and were given didactic information and experiential training in the use of sexual barrier products with anatomical models. Participants also learned about the health and social effects of recreational drugs, alcohol, and smoking on HIV medication, disease progression, and health using a brief videotape to stimulate group discussion. Finally, the physical activity component emphasized the importance of aerobics, strength training, and flexibility to increase their activity levels.

The first three sessions of Healthy Living were information intensive and focused on health behavior acquisition, practice, and maintenance; the fourth and fifth sessions emphasized relapse prevention skills. The final session summarized the Healthy Living material and applied CBSM strategies to incorporating the health behavior messages, eg, problem solving, cognitive restructuring, and coping strategies.

\section{Individual (attention control) condition}

In designing these studies, the research team was faced with a serious ethical dilemma: whether to include a "true" control condition that would have no discernible health benefit for the participants. Due to the fragile health status of the study population, it was agreed that no true "placebo" would be used, and that both the "group" and "individual" conditions would be considered "active", ie, intended to convey clinical benefit. The research team felt that under these circumstances it would be appropriate to vary the intensity of the program, keeping exposure to the health-enhancing information equivalent with differing modes of delivery.

In both SWP I and SWP II, each participant in the individual condition was invited to attend a weekly appointment of equal length to the group session, during which time the participant viewed videotapes related to stress management/ relaxation training and coping with HIV. A professional staff member was available to answer questions during the session. The informational/educational videos were supplemented with entertainment videos to adhere to the similar "attention" time requirement (135 minutes). Participants randomized to the individual condition selected and viewed an entertainment video film each session (after the designated informational/ educational video) to match the time period of the group condition and to maintain motivation for continued participation in the study.

\section{Study hypotheses}

In both SWP I and SWP II using "intent-to-treat" analyses, the group condition was compared with an Individual Health Promotion condition. ${ }^{1}$ Benefit was expected as a result of exposure to either condition, with the experimental hypotheses favoring the more time- and cost-efficient group condition. ${ }^{27}$ Consistent with this rationale, we conducted subgroup analyses which considered "pre-post" treatment differences in both conditions in addition to the traditional condition $\times$ time analyses. We also identified subgroups within the larger sample, eg, participants who at study entry were more depressed, or were low medication adherers, high sexual risk-takers, or active substance abusers, and followed their short- and long-term progress from baseline. Although these analyses departed somewhat from traditional clinical trial design of "intent-to-treat", we believe the ethical issues involved justified the attenuation of study design rigor.

For SWP II, it was hypothesized that exposure to the $\mathrm{CBSM}+$ group intervention would provide a more supportive environment for an intensive HIV-related health behavior change program devoted to maintaining optimum health in the long-term management of HIV. Specifically, participation in the groups, facilitated by experienced group leaders was hypothesized to promote increased medication adherence, improved nutritional practices, greater utilization of safer sexual practices, more vigorous physical activity patterns, and reduced substance abuse as compared with the "equal information" individual condition. Using a full factorial design enabled us to determine whether CBSM+ significantly improved adherence to any or all of the health-related behaviors addressed in this study and how a standard educational/ informational experience in CBSM+, Healthy Living, or both, compared with one or both sessions of group experience.

\section{Results}

The following previously published and original findings contained in this paper are from two consecutive studies from the SWP I (1996-2000) and SWP II (2001-2006) projects.

\section{General analytic approach}

Traditional repeated measures analyses of variance (RMANOVA) were used to test the effectiveness of the 
CBSM+ group intervention during SWP I. For SWP II, multilevel models (MLMs) using MLwin 2.0 $0^{28-30}$ with three levels (treatment group, language, time) were fitted for each outcome to adjust for the intraclass correlations which may result when subjects are nested within sites and subjects were measured repeatedly over time. The three-level models were equivalent to a two-by-two analysis of covariance (ANCOVA) with the first main factor representing the initial intervention and the second main factor representing the health promotion intervention. The term $T$ (time in months since baseline examination) and its interactions describe the overall trend (slope) of the four groups over the course of the study. In the MLM analyses reported here, lines were fitted to the data for each outcome in each of the four intervention groups and also for two groups which permitted contrasts between participating in any group condition versus the individual condition for the entire 16-week intervention period. Approximate $P$-values for each coefficient and calculated slope were determined by Wald's test and Chi-square tests. Deviance tests were used to assess overall improvement as additional terms were introduced into the model. Each outcome was modeled separately and a residuals analysis was conducted.

The slopes of these lines were interpreted as the average rate of change for the intervention group over the 24-month follow-up period. When appropriate, the outcome variables were mathematically transformed or data from specified subgroups of study subjects were analyzed separately. These models provided estimates of the intercept and slope of a line fitted to the data in each of the four randomized intervention groups, and analyses estimated the effect of receiving any form of group intervention versus individual condition. Participants were followed for up to 12 months in SWP I and for 24 months in SWP II. The overall attrition rate for both studies was approximately $20 \%$. All results are reported here as significant ( $P<0.05$; unadjusted for multiple comparisons).

\section{Quality of life SWP I}

Results of the two (condition: group versus individual) by two (time: pre- versus post-intervention) RMANOVAs revealed significant effects for time for the total QoL score, cognitive functioning, health distress, and overall health perceptions, such that women in both conditions improved over the course of the study. In addition, a significant group by time interaction was noted for mental health QoL such that participants in the CBSM+ group showed a significant increase in QoL from pre- to post-intervention, whereas individual condition participants showed no such change. ${ }^{31}$

\section{SWP II}

Overall, the slopes revealed that there was a significant increase in mental health QoL for participants who received any group treatment $(P<0.05)$, and no significant increase for individual condition participants.

\section{Depression and anxiety SWP I}

Acquisition of CBSM+ skills was associated with decreased symptoms of depression and anxiety $(P<0.05) .{ }^{32}$ We also identified intervention effects on a subgroup of 154 women who presented with clinically elevated depression. A RMANOVA (using SAS PROC MIXED; SAS Institute, Cary, NC) revealed a significant condition by time interaction for both BDI total and the somatic subscale. A "within condition" simple effects ANOVA demonstrated a significant decrease in both the CBSM+ group condition and individual condition for BDI total, and somatic and cognitive subscales. ${ }^{32}$ Across treatment conditions, perceived changes in the acquisition of cognitive behavioral skills (as assessed by the cognitive-behavioral self-efficacy [CB-SE] scale) were associated with reduction in depression. However, the effects were greatest for those who participated in the CBSM+ group, suggesting that learning in context with others produces a more effective outcome. In addition, there was a significant inverse interaction between changes in CB-SE and depression, as well as anxiety, regardless of condition assignment. ${ }^{33}$ For CBSM+ only, increases in CB-SE were significantly correlated with decreases in both BDI $(r=-0.263)$ and state anxiety $(r=-0.361)$ scores.

\section{SWP II}

Group interventions also significantly reduced depression for moderately depressed participants $(P<0.01)$, significantly increased mental health QoL $(P<0.05)$, and significantly decreased log viral load (VL) only in the CBSM+ group condition $(P<0.01)$. Furthermore, SWP II significantly improved dietary behaviors, ${ }^{34}$ reduced sexual risk, ${ }^{35}$ and reduced alcohol usage $(P<0.05)$.

We also replicated the intervention effects on subgroups of depressed women in SWP II. The analyses examined the main effects of time, treatment, and the group by time interaction, and follow-up analyses examined the degree to which the slope for each condition differed from zero. The analyses were conducted for both the entire sample $(n=482)$ and for those participants who were moderately depressed at baseline (BDI score $>10, n=245$ ). None of the four groups differed in any of the depression scores at baseline. The data 
revealed a significant effect of time on all three depression scores (BDI total, BDI somatic, BDI cognitive) $(P<0.05)$. Across the entire sample, the slope is significantly less than zero indicating that there is an overall decline of BDI total with time of 0.026 per month. Among those with moderate depression (BDI $>10)$, there is an overall decline in slope over time of about 0.146 per month for those in the most distressed state. The slopes for those moderately depressed participants who had received any group-based intervention differed significantly from zero over 24 months $(P<0.01)$; depressed individual condition participants did not change significantly over the same time period.

\section{Medication adherence SWP I}

For those women who reported low ARV adherence $(<90 \%)$ at baseline, self-reported adherence revealed a significant increase over baseline in adherence for the CBSM+ group $(\mathrm{t}[44]=3.08, P<0.01)$. In a RMANOVA, the main effect of condition (CBSM+ group, individual) by time (pre- and post-intervention) was significant $(P<0.05)$, with $35 \%$ of the "low adherers" reporting that they increased their level of adherence to $95 \%$ or greater. ${ }^{36,37}$

Additional analyses of the SWP I data examining low medication adherence and drug use revealed that former drug users who were in recovery demonstrated significantly greater gains in medication adherence $(P<0.01)$ as well as reduced viral load $(P<0.01)$ as compared with current users or "never" users as a result of participation in the intervention. ${ }^{38}$

\section{SWP II}

The slopes revealed that participants with less than $90 \%$ adherence at baseline increased medication adherence significantly in both the CBSM+ group and individual condition $(P<0.01)$. Participants in the any group condition had an increase in ARV adherence, in contrast to the individual condition $(P<0.05)$. Group participants increased their emotion-focused coping skills related to adherence $(P<0.05)$ and reported a decrease in the number of reasons for missing doses and maintenance of positive medicationrelated beliefs. ${ }^{36-38}$

\section{HIV viral load SWP I}

There were no significant main effects of treatment and no significant treatment by time interaction on VL. Follow-up analyses examined the effects of treatment group and changes in CB-SE skills acquired during treatment on changes in VL and CD4 cell count. For the CBSM+ group, increases in CB-SE were significantly correlated with decreases in VL over time (post-intervention, $r=-0.284$; 6-month follow-up, $r=-0.418$; 12-month follow-up, $r=-0.275$; all $P<0.05$ ). Increases in AIDS self-efficacy (AIDS-SE) were also significantly correlated with increases in CD4 cell count at post-intervention ( $r=0.269 ; P<0.05)$, although this improvement was not maintained at follow-up. These results suggest that improving self-efficacy is related prospectively to both improved disease and health status. ${ }^{39}$

\section{SWP II}

Among the high-risk patients $(n=451)$ defined as those with detectable viral loads at baseline ( $>400$ copies/mL), VL decreased significantly over 24 months only in the CBSM+ group condition $(P<0.01)$ and not in the individual condition (see Figure 2A). An additional analysis broken down by location (Miami versus NY/NJ) demonstrated that VL decreases in the group condition were noted in both Miami and NY/NJ $(P<0.001)$, but not in the individual condition in either location ${ }^{40}$ (see Figure $2 \mathrm{~B}$ ). An additional observation highlights the relative differences in baseline VLs in Miami as compared with New York, suggesting there may be different regional treatment strategies, (ie, more aggressive ARV treatment in New York), which must be considered in future intervention trials.

\section{Sexual risk reduction and domestic violence SWP II}

At baseline, the mean number of sexual acts was $2.9 \pm 2.6$ per week. The mean number of protected acts was $1.4 \pm 2.3$, with $56 \%$ of the participants reporting no protected acts. The probability of unprotected sex was calculated by dividing the number of protected acts by the total number of acts. The results of a mixed modeling procedure show that the group intervention significantly decreased the unprotected sex odds ratio from 0.162 to $0.095(\mathrm{~F}[1,220,122]=0.04, P<0.038)$. Group participants also increased use of vaginal sexual barriers with no decreased use of male condoms $(P<0.05)$.

\section{Alcohol and substance abuse SWP II}

No differences were observed between conditions. A one-way RMANOVA comparing drug and alcohol use at three different times: baseline, 6 months, and 12 months follow-up demonstrated a significant reduction in alcohol 

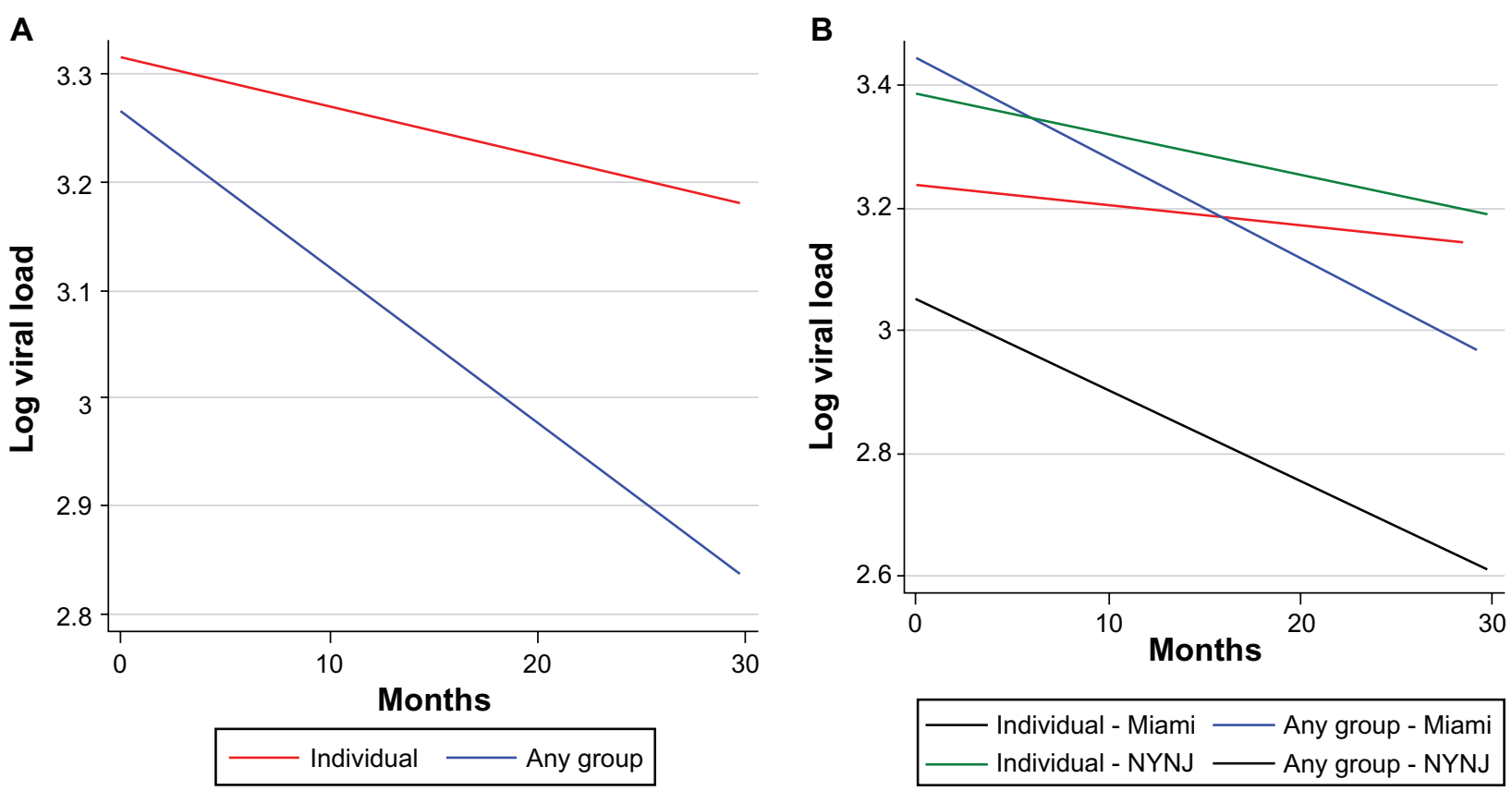

Figure 2 A) Log viral load, group and individual conditions over time. B) Log viral load, any group and individual condition by site. Abbreviation: NYNJ, New York/New Jersey.

use between baseline and 12 months follow-up in both conditions $(\mathrm{F}[2,486]=3.39, P<0.05)$. No changes were noted for drug use.

\section{Nutrition SWP II}

A one-way RMANOVA compared the scores of the Rapid Eating and Activity Assessment for Patients (REAP) questionnaire $^{41}$ (total, sugar, fat, vegetables, fruit). No differences were noted at baseline between the conditions. Dietary patterns improved after the nutrition intervention for the entire sample and were still significantly better at 24 months postbaseline. Significant effects $(P<0.05)$ were found for REAP total, sugar, and fat. ${ }^{40}$ Group participants initially improved more than those who did not, but there were no differences between conditions by 24 months post-baseline.

\section{Physical activity SWP II}

At baseline, there were no differences in self-reported duration of daily walking activity between women assigned to the group ( $21 \pm 8$ minutes/day) or individual ( $24 \pm 7$ minutes/ day) conditions. A RMANOVA from baseline to postintervention revealed the main effect for time was significant (F $[2,39]=12.6, P<0.01)$, with women in both conditions increasing their walking activity to 62 and 51 minutes/day, respectively.

\section{Cultural/linguistic effects}

Analyses were conducted to determine whether the effects of the intervention for Spanish- and Creole-speaking women were the same as those for English-speaking women. Overall, these analyses suggest that there were no significant differences among the English- Spanish- and Creole-speaking groups with regard to the behavioral and health status outcomes. The overall findings indicate that the cultural brokerage process and linguistic translations were effective in adapting the intervention to the needs of all three cultural/ linguistic groups. See Table 4.

\section{Discussion}

The participants in these two studies, nearly 1000 poor, predominantly African-American, Hispanic, and HaitianAmerican women living with HIV, drawn from three of the major epicenters for HIV infection in this country (South Florida, New York, and New Jersey), represent seriously underserved segments of the United States HIV+ population. The primary objective of these studies was to determine whether a behavioral intervention strategy previously found to be effective with middle-class gay men could be tailored to the needs of disadvantaged, ethnically diverse women.

Over the 10-year history of the two studies, dramatic improvement of treatment options occurred with the advent of combination therapy with ARVs, converting a life-threatening disease into a potentially chronic, yet manageable, condition. 
Table 4 Summary of study outcomes

\begin{tabular}{|c|c|c|}
\hline Study and domain & SWP I & SWP II \\
\hline QoL & $\begin{array}{l}\text { Improved QoL, cognitive functioning, health } \\
\text { distress, overall health perceptions and mental health }\end{array}$ & Improved QoL mental health \\
\hline Depression and anxiety & Decreased depression and anxiety & Decreased depression \\
\hline Medication adherence & Increased ARV adherence & $\begin{array}{l}\text { Increased ARV adherence among low adherers, increase in } \\
\text { emotion- focused coping skills related to adherence, and } \\
\text { decrease in number of reasons for missing dose }\end{array}$ \\
\hline VL & $\begin{array}{l}\text { Increased CB-SE skills related to decreases in VL and } \\
\text { AIDS-SE related to increases in CD4 count over time }\end{array}$ & VL decreased \\
\hline $\begin{array}{l}\text { Sexual risk reduction } \\
\text { and domestic violence }\end{array}$ & N/A & $\begin{array}{l}\text { Decreased unprotected sex and increased use of vaginal } \\
\text { sexual barriers }\end{array}$ \\
\hline Alcohol and drug use & N/A & No changes noted \\
\hline Nutrition & N/A & Dietary patterns improved for REAP total, sugar, and fat \\
\hline Physical activity & N/A & Increased walking activity for minutes/day \\
\hline
\end{tabular}

Note: These outcomes were not assessed in SWP I.

Abbreviations: AIDS-SE, acquired immunodeficiency syndrome self-efficacy; ARV, antiretroviral therapy; CB-SE, cognitive-behavioral self-efficacy; N/A, not applicable; QoL, quality of life; SWP I/II, stress management and relaxation training/expressive-supportive therapy (SMART/EST) Women's Program - first study/second study; VL, viral load.

With the increase in life expectancy among HIV+ patients, new challenges have emerged in terms of effective disease management for patients living with HIV. The increases in survival have been accompanied by new clinical issues, including lipodystrophy, increases in cardiovascular risk and diabetes ${ }^{41}$ and relapses in high-risk behaviors including increases in drug use and unsafe sexual practices..$^{42}$ All of these phenomena can be considered as potential stressors, and our interventions were designed to provide the skills to facilitate adjustment to these contemporary challenges of living with HIV.

The overall findings from the two studies suggest that the CBSM+ intervention combined with Healthy Living components was effective in reducing distress, improving QoL, as well as reducing sexual risk, improving medication adherence, and reducing alcohol abuse. Pre-post subgroup analyses also identified salutary changes in nutrition, VL, and physical activity. There were, however, no comparable findings for drug abuse; that is, no significant changes in drug use/abuse were noted.

Of specific interest is the finding that the intervention appeared to be equally effective with less-acculturated women who were monolingual in Spanish or Creole. Special efforts were made through the "cultural brokerage" process to make the content and structure of the sessions consistent with the values and mores of the Hispanic and Haitian cultures. For example, issues concerning stigma and disclosure were more heavily emphasized in the sessions to reflect their importance within these groups.

It must be remembered that our study participants were selected on the basis of their HIV status rather than on the basis of specific behavioral, psychological, or sociological diagnoses or characteristics. Although we anticipated that there would be more psychosocial, behavioral, and psychiatric problems among our participants based upon their HIV infection and socioeconomic status, we also recognized that the majority of participants would not qualify as "depressed, anxious, nonadherent, or substance abusing". This was reflected, for example, in the "main effects" analyses for depression, where we found no significant effect of the intervention on reducing depression for the entire intervention population. However, when we restricted the analysis to only those who entered the study moderately depressed, then a significant difference was noted in the experimental condition as compared with the control condition.

Taking each of the findings in turn, it is notable that only a third of our participants qualified as "moderately" depressed at study entry. As noted above, severely depressed study candidates were temporarily excluded and requested to seek treatment prior to becoming eligible for study enrollment. Although we found that the intervention significantly reduced depression in the intervention versus control condition, the generalizability of the finding is limited by the study inclusion/exclusion criteria.

Similarly, a minority of our participants were considered "nonadherent" with respect to antiretroviral medications. Again, the overall "main effects" analysis showed no significant improvement in medication adherence in the intervention participants. Only when the "low adherers" were identified was a treatment outcome noted which demonstrated significant improvement in medication adherence for low adherers in the intervention condition compared with the control condition. 
Finally, improvements in daily walking were noted in both conditions, suggesting that they may have been the result of physical ailment relief associated with treatment rather than the physical activity aspects of the intervention.

These two studies taken together have demonstrated the feasibility of implementing a comprehensive group-based behavioral and lifestyle intervention to provide services to HIV+ women in both academic and community-based primary care settings using a CBSM+ framework. The study was designed to intervene on a wide range of clinical and psychosocial needs of multicultural HIV+ female patients seen in primary care settings, and all components of the intervention did not apply to every patient. While intent-to-treat analyses conducted for all primary and secondary outcomes did not demonstrate significant group $\times$ time effects, to evaluate the impact of the intervention on specific at-risk patients, subgroups of high-risk patients were identified and analyses were repeated with respect to the specific outcomes (ARV adherence, condom use, etc). The majority of high-risk subgroup analyses conducted demonstrated significant improvements in most of the interventions, which enhances the feasibility and efficacy of delivering group-based behavioral interventions to diverse patient populations, and supports widespread dissemination and adoption of the protocol.

The significant findings within these clinically important subgroups are impressive when compared with the only other large-scale intervention study (nonrandomized) in similar service settings. In 2004, Landon et $\mathrm{al}^{43}$ assessed the effectiveness of a quality improvement collaborative that focused upon improving the quality of care of HIV-infected patients. In a rigorously controlled pre- and post-intervention study, no significant effect on the quality of care was found. In an accompanying article, Mittman ${ }^{11}$ strongly advised that future collaboratives ought to be subjected to thorough evaluation to elucidate the conditions that result in best outcomes from the intervention. ${ }^{44} \mathrm{He}$ also stated that "researchers must recognize the heterogeneity of individual applications of the collaborative method and the limited value of conventional synthesis methods that are better suited to clinical evidence than evidence in the management, behavioral, and social sciences". These comments emphasize the challenges of balancing high levels of implementation fidelity with flexibility, protocol drift, and local adaptation that may happen over time, and the value of subgroup analyses to identify those populations most likely to benefit from such interventions.

\section{Dissemination: the next frontier}

The challenges associated with moving effective interventions from research to practice are substantial and require attention to issues including training, treatment fidelity, staffing, resource allocation, finance, and reimbursement. ${ }^{43}$ Glasgow et $\mathrm{al}^{8}$ have proposed a framework called "RE-AIM" (Reach, Efficacy, Adoption, Implementation, Maintenance), which accounts for dimensions for evaluation on the individual patient and the adopting organization levels. The RE-AIM framework has proposed that the estimate of program impact on a population is the product of its reach, efficacy, and implementation, while on the organizational level; the impact estimate is the product of adoption and implementation. ${ }^{46}$ This approach provides a multilevel framework to examining the individual and organizational levels of adoption of innovations ${ }^{47}$ and change.

To that end, a new study funded by the Centers for Disease Control and Prevention is underway, training health professional and allied health care staff to deliver the 16-session manualized intervention. Using Glasgow's RE-AIM model as the theoretical basis for translating evidenced-based interventions into health practice, this study is disseminating these strategies into community health settings recruited from an established national system of primary care: HRSA Primary Care and Ryan White grantees. The results of this program will have significant implications for the feasibility of the integration of the SWP with behavioral and mental health services, and improving health outcomes for all women living with HIV.

\section{Disclosure}

The authors report no conflicts of interest in this work.

\section{Acknowledgements}

These studies have been supported by research grants from the US National Institute of Mental Health, NIH (R01MH55463 and ROIMH61208) and the US Centers for Disease Control and Prevention (R18PS000829).

\section{References}

1. Centers for Disease Control and Prevention. HIV/AIDS Surveillance Report, 2008. Vol. 20. Atlanta: US Department of Health and Human Services, CDC; http://www.cdc.gov/hiv/topics/surveillance/resources/ reports/Published 2010 June. Accessed 2010 Oct.

2. The New York City Department of Health and Mental Hygiene. HIV Epidemiology and Field Services Semiannual Report. 2008;3(1): $1-4$

3. AVERT. HIV and AIDS statistics by state (2009). Available from: http:// www.avert.org/usa-states-cities.htm. Accessed 2010 Oct 12.

4. Miami-Dade County Health Department. AIDS Surveillance. 2007. 
5. Florida Department of Health. Florida Annual Report (2005). Available from: http://www.flpublichealth.com/VSBOOK/VSBOOK.aspx. Accessed 2010 Oct 12.

6. Corbett M, Dickson-Gomez J, Hilario H, Weeks M. A little thing called love: condom use in high-risk primary heterosexual relationships. Perspect Sex Reprod Health. 2009;41(4):218-224.

7. Centers for Disease Control and Prevention. HIV/AIDS Surveillance Report, 2007. Vol 19. Atlanta: US Department of Health and Human Services, Centers for Disease Control and Prevention; 2009:1-63. Available from: http://www.cdc.gov/hiv/topics/surveillance/resources/reports/. Accessed 2010 Oct 12.

8. Glasgow ER, Lichtenstein E, Marcus AC. Why don't we see more translation of health promotion research to practice? Rethinking the efficacy-to-effectiveness translation. Am J Public Health. 2003;93(8):1261-1267.

9. Navarro A, Voetsch K. Liburd L, Giles W, Collins J. Charting the future of community health promotion: recommendations from the National Expert Panel on community health promotion. Prev Chronic Dis. 2007;4(3):1-7.

10. Kelly JA, Somlai AM, di Franceisco WJ, et al. Bridging the gap between the science and the service of HIV prevention: transferring effective research-based HIV prevention interventions to community AIDS service providers. Am J Public Health. 2002;90:1082-1088.

11. Mittman BS. Creating the evidence base for quality improvement collaboratives. Ann Intern Med. 2004;140(11):897-901.

12. Fals-Stewart W, Logsdon T, Birchler GR. Diffusion of an empirically supported treatment for substance abuse: an organizational autopsy of technology transfer success and failure. Clin Psychol Sci Pract. 2004;11(2):177-182.

13. Côté J, Godin G, Garcia PR, Gagnon M, Rouleau G. Program development for enhancing adherence to antiretroviral therapy among persons living with HIV. AIDS Patient Care STDS. 2008;22(12):965-975.

14. Richard N, Juntilla M, Abraha A, et al. High prevalence of antiretroviral resistance in treated Ugandans infected with non-subtype B human immunodeficiency virus type 1. AIDS Res Hum Retroviruses. 2004; 20(4):355-364.

15. Velozzi C, Brooks J, Bush T, et al. The Study to understand the natural history of HIV and AIDS in the era of effective therapy. Am J Epidemiol. 2008;169:642-652.

16. Paterson DL, Swindells S, Mohr J, et al. Adherence to protease inhibitor therapy and outcomes in patients with HIV infection. Ann Intern Med. 2000;133(1):21-30.

17. Hamburger ME, Moore J, Koenig LJ, et al; for the HIV Epidemiology Research Study Group. Persistence of inconsistent condom use: relation to abuse history and HIV serostatus. AIDS Behavior. 2004;8(3): 333-344.

18. Uphold C, Holmes W, Reid K, Findley K, Parada J. Health lifestyles and health related quality of life among men living with HIV infection. J Assoc Nurses AIDS Care. 2007;18(6):54-66.

19. Antoni MH, Ironson G, Schneiderman N. Stress Management for Persons with HIV Infection. New York: Oxford University Press; 2007.

20. First MB, Spitzer RL, Gibbon M, Williams JB. The Structured Clinical Interview for DSM-III-R (SCID): I. History, rationale, and description. Arch Gen Psychiatry. 1992;49:624-629.

21. Spitzer RL, Williams JB, Gibbon M, First MB. Structured Clinical Interview for DSM IIIR - Non-patient Version for HIV Studies. NY State Psychiatric Institute: Biometrics Research Department; 1988.

22. Erkut S, Alarcon O, Garcia-Coll C, Tropp LR, Vazquez-Garcia HA. The dual-focus approach to creating bilingual measures. J Cross-Cultural Psychol. 1999;30(2):206-218.

23. Herdman M, Fox-Rushby J, Badia X. Equivalence and the translation and adaptation of health-related quality of life questionnaires. Qual Life Res. 1997;6(2):237-247.

24. Hilton A, Skrutkowski M. Translating instruments into other languages: development and testing processes. Cancer Nurs. 2002;25(1):1-7.

25. Forsythe CJ, Compas B. Interaction and cognitive appraisals of stressful events and coping. Cogn Behav Ther. 1987;11:473-485.
26. Folkman S, Chesney M, McKusick L, Ironson G, Johnson D, Coates T. Translating coping theory into intervention. In: Mckenrode J, editor. The Social Context of Stress. New York: Plenum; 1991.

27. Gore-Felton C, Rotheram-Borus MJ, Weinhardt LS, et al. The Healthy Living Project: an individually tailored, multidimensional intervention for HIV-infected persons. AIDS Education Prevalence. 2005;17 Suppl 1:21-39.

28. Bryk SW, Raudenbush AS. Hierarchical Linear Models: Applications and Data Analysis Methods. 2nd ed. Newbury Park, CA: Sage Publications; 2002.

29. Goldstein H. Kendall's Library of Statistics 3, Multilevel Statistical Methods. 3rd ed. London: Hodder Arnold; 2002.

30. Hox J. Multilevel Analysis: Techniques and Applications. Mahwah, NJ: L Earlbaum Assoc; 2002.

31. Lechner SC, Antoni MH, Lydston D, et al. Cognitive-behavioral interventions improve quality of life in women with AIDS. J Psychosom Res. 2003;54:253-261.

32. LaPerriere A, Ironson G, Antoni MH, et al. Decreased depression up to one year following CBSM+ intervention in depressed women with AIDS: the SMART/EST Women's Project. J Health Psychol. 2005; 10(2):223-231.

33. Jones D, Ishii M, Lydston D, Brondolo E, Tobin JN, Weiss SM. Cognitive-behavioral skills training in group-based CBSM+ intervention improves anxiety and depression in women with AIDS. AIDS Care. In press 2010.

34. Tobin JN, Weiss SM, Ishii M, et al. Translation of a behavioral intervention to promote HAART adherence from the academic to the community health center setting. Presented at the 2nd International Conference on HIV Treatment Adherence (International Association of Physicians in AIDS Care), Jersey City, NJ. March 30, 2007.

35. Jones DL, Weiss SM, Bhat GJ, Feldman DA, Bwalya V, Budash D. A Sexual Barrier Intervention for HIV+/- Zambian Women: Acceptability and Use of Vaginal Chemical Barriers. Journal of Multicultural Nursing and Health. 2004;10:27-31.

36. Jones DL, McPherson-Baker S, Lydston D, et al. Efficacy of a group medication intervention among HIV positive women: the SMART/EST Women's Project. AIDS Behavior. 2007;11(1):79-86.

37. Jones D, Ishii M, LaPerriere A, et al. CBSM+ and medication adherence among women with AIDS: the SMART/EST Women's Project. AIDS Care. 2003;15(4):463-474.

38. Lopez EJ, Jones DL, Ishii M, Tobin JN, Weiss SM. HIV medication adherence and substance use: the SMART/EST Women's Project. Am J Infect Dis. 2007;3(4):239-246.

39. Ironson G, Weiss S, Lydston D, et al. The impact of improved selfefficacy on HIV viral load and distress in culturally diverse women living with AIDS. AIDS Care. 2005;17(2):222-236.

40. Segal-Isaacson CJ, Tobin JN, Weiss SM, et al. Improving dietary habitsin disadvantaged women with HIV/AIDS: the SMART/EST Women'sProject. AIDS Behav. 2006;10(6):659-670.

41. Gans K, Sundaram S, McPhillips J, Hixson M, Linnan L, Carleton R. (1993). Rate Your Plate: An Eating Pattern Assessment and Educational Tool Used at Cholesterol Screening and Education Programs. Society for Nutrition Education. 25(1):29-36.

42. Worm SW, Sabin C, Weber R, et al. Risk of myocardial infarction in patients with HIV infection exposed to specific individual antiretroviral drugs from the 3 major drug classes: the data collection on adverse events of anti-HIV drugs (D:A:D) study. $J$ Infect Dis. 2010;201: $318-330$.

43. Kalichman S. The synergies of HIV treatment, adherence and prevention. Future HIV Ther. 2007;1(2):145-148.

44. Landon BE, Wilson IB, McInnes K. Effects of a quality improvement collaborative on the outcome of care of patients with HIV infection: The EQHIV. Ann Intern Med. 2004;140:887-901.

45. Wagner EH, Glasgow RE, Davis C, et al. Quality Improvement in chronic illness: a collaborative approach. Jt Comm J Qual Improv. 2001;27(2):63-80. 
46. DiFranceisco W, Kelly JA, Otto-Salaj L, et al. Factors influencing attitudes within AIDS service organizations toward the use of research-based HIV prevention interventions. AIDS Educ Prev. 1999;11(1):72-86.

47. Anaya HD, Yano EM, Asch SM. Early adoption of human immunodeficiency virus quality improvement in Veterans Affairs medical centers: use of organizational surveys to measure readiness to change and adapt interventions to local priorities. Am J Med Qual. 2004;19(4):137-144.

48. Rogers EM. Diffusion of Innovations. 5th ed. New York, NY: The Free Press; 2003.

49. Schneiderman N. Behavioral medicine and the management of HIV/ AIDS. Int J Behav Med. 1999;6:2-14.

50. Beck AT, Ward CH, Mendelson M, Mock J, Erbaugh J. An inventory for measuring depression. Arch Gen Psychiatry. 1961;4(6):561-571.

51. Spielberger CD, Gorsuch RL, Lushene R, Vagg PR, Jacobs GA. State-Trait Anxiety Inventory (Form Y). Palo Alto, CA: Mind Garden; 1983.

52. Horowitz M, Wilner N, Alvarez W. Impact of Event Scale: a measure of subjective stress. Psychosom Med. 1979;41(3):209-218.

53. Wu AW, Rubin HR, Mathews WC, et al. A health status questionnaire using 30 items from the Medical Outcomes Study: preliminary validation in persons with early HIV infection. Med Care. 1991;29:786-798.

54. Chesney MA, Ickovics JR, Chambers DB, et al; for the Patient Care Committee and Adherence Working Group of the Outcomes Committee of the Adult AIDS Clinical Trials Group (AACTG). Selfreported adherence to antiretroviral medication among participants in HIV clinical trials: the AACTG adherence instrument. AIDS Care. 2000;12:255-266.

55. Meyer-Bahlburg HFL, Ehrhardt AA, Exner TM, Gruen RS. Sexual Risk Behavior Assessment Schedule: Adult (SERBAS-A-DF-4) Manual; 1990.

56. Family Health International. Acceptability Assessment Vaginal Microbicide Study. HIVNET, Statistical and Clinical Coordinating Center; 1996.

57. Gans KM, Ross E, Barner CW, Wylie-Rosett J, McMurray J, Eaton C. REAP and WAVE: new tools to rapidly assess/discuss nutrition with patients. J Nutrition. 2003;133(2):S556-S562.

58. Sallis J, Haskell W, Wood P, Fortmann S, Rogers T, Blair S, et al. Physical activity assessment methodology in the five-city project. Am J Epidemiol. 1985;121:91-106.

59. Ironson G. Miami Alcohol Use Questionnaire. Unpublished Instrument.

60. Kaminsky S, Kurtines W, Blaney NT, Szapocznik J. Social Service Utilization Schedule. Unpublished Instrument, Department of Psychology: University of Miami; 1989.

61. Karnofsky D, Abelmann W, Craver L, Burchenal J. The use of the nitrogen mustards in the palliative treatment of carcinoma. Cancer. 1948;1:634-652.
62. Szapocznik J, Scoppetta M, Kurtines W, Aranalde M. Theory and measurement of acculturation. Interam J Psychol. 1978;12:113-130.

63. Szapocznik J, Kurtines WM, Fernandez T. Bicultural involvement and adjustment in Hispanic-American youths. Int J Intercult Relat. 1980;4: 353-364.

64. Szapocznik J, Kurtines WM. Family psychology and cultural diversity: Opportunities for theory, research, and application. Am Psychol. 1993; 48(4):400-407.

65. Tropp LR, Erkut S, Alarcon O, Garcia-Coll C, Vazquez H. Psychological acculturation: development of a new measure for Puerto Ricans on the US mainland. Educ Psychol Meas. 1999;59(2):351-367.

66. Carver C, Sheier M, Weintraub JD. Assessing coping strategies: a theoretically-based approach. J Pers Soc Psychol. 1989;56: 267-283.

67. Power C, Selnes OA, Grim JA, McArthur JC. HIV Dementia Scale: a rapid screening test. J Acquir Immune Defic Syndr Hum Retrovirol. $1995 ; 8: 273-278$

68. Folstein MF, Folstein SE, McHugh PR. "Mini-mental state": a practical method for grading the cognitive state of patients for the clinician. J Psychiatr Res. 1975;12:189-198.

69. Ironson G, Friedman A, Klimas N, et al. Distress, denial and low adherence to behavioral interventions predict faster disease progression in HIV-1 infected gay men. Int J Behav Med. 1994;1(1):90-105.

70. Hinkle YA, Antoni MH, Schneiderman N, Ironson G, Efantis J, Johnson EH. Psychosocial correlates of stress and anxiety among African-American women who are HIV-positive and HIV-negative. Ann Behav Med. 1994;16:183.

71. Sarason IG, Levine HM, Basham RB, Sarason BR. Assessing social support: the Social Support Questionnaire. J Pers Soc Psychol. 1983; 44:127-139.

72. Winters MA, Tan LB, Katzenstein DA, Merigan TC. Biological variation and quality control of plasm HIV-1 RNA quantitation by reverse transcriptase chain reaction. J Clin Microbiol. 1993:31: 229-244.

73. Kidd P, Nicholson J. Immunophenotyping by flow cytometry. In: Rose N, Conway de Macario E, Folds J, et al, editors. Manual of Clinical Laboratory Immunology. 5th ed. ASM Press; 1997:229-244.

74. Burczak J, Ching S, Hu H, Lee H. Ligase chain reaction for the detection of infectious agents. In: Wiedebrank D, Farkas D, editors. Molecular Methods for Virus Detection. San Diego, CA: Academic Press, Inc.; 1995:315-328.

75. Public Health Service Publication No. 411 (1969). Testing Manual for Syphilis.

76. Segal KR, van Loan M, Fitzgerald PI, Hodgdon JA, van Itallie TB. Lean body mass estimation by bioelectrical impedance analysis: a four-site cross-validation study. Am J Clin Nutr. 1988;47(1):7-14.

77. Coodley GO, Coodley MK, Nelson HD, Loveless MO. Micronutrient concentrations in the HIV wasting syndrome. AIDS. 1993;7(12):1595-1600.
International Journal of Women's Health

\section{Publish your work in this journal}

The International Journal of Women's Health is an international, peerreviewed open-access journal publishing original research, reports, reviews and commentaries on all aspects of women's healthcare including gynecology, obstetrics, and breast cancer. Subject areas include Chronic conditions (migraine headaches, arthritis, osteoporosis);

\section{Dovepress}

Endocrine and autoimmune syndromes; Sexual and reproductive health; Psychological and psychosocial conditions. The manuscript management system is completely online and includes a very quick and fair peer-review system. Visit http://www.dovepress.com/ testimonials.php to read real quotes from published authors. 